\title{
Ruggiero Romano y la historia económica: legados y adeudos
}

\author{
Antonio Ibarra ${ }^{1} *$ * (D) 0000-0003-0169-9979
}

${ }^{1}$ Universidad Nacional Autónoma de México, México.

*Correspondencia:ibarrara@unam.mx

El de 6 enero de 2002 leímos la noticia del fallecimiento de Ruggiero Romano a causa de su precaria salud por el cáncer y la fatiga, él murió en París, su centro académico y refugio de reflexiones intelectuales ${ }^{1}$ Con seguridad, la recepción de esta noticia nubló el día de muchos de nosotros, pero también nos hizo volver los ojos a lo que ya había dejado impreso en el papel y en los recuerdos de quienes le conocieron durante una vida de pasión intelectual por la historia ${ }^{2}$ Entre sus alumnos y colegas, su memoria evoca recuerdos agridulces de sus críticas y enseñanzas. Quizá algún polemista herido por la mordaz crítica de Romano, que los procuraba, sintió nostalgia por una presencia incómoda pero invaluable.

Alumnos y lectores de Romano extrañamos su vigilante presencia historiográfica, tal vez debemos habituarnos a prescindir de su vigor polémico verbal y retomar sus aceradas opiniones escritas, tan oralmente apasionadas muchas de ellas. En cualquier caso, Ruggiero murió, y puedo imaginar que murió satisfecho de su vida, aunque aún dejó proyectos intelectuales por realizar, como lo muestra la escritura de su último libro tan solo un semestre antes de su deceso 3 Para un hombre que vivió intensamente sus 78 años, la fatiga puede ser también explicada a partir de los

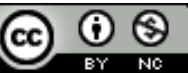

Esta obra está protegida bajo una Licencia Creative Commons Atribución-NoComercial 4.0 Internacional

1 “E morto l'altra notte all' hospédale americano di Neully, a Parigi, assistito fino all'ultimo dalla sua compagna Frncoise Braudel, figlia del grande storico francese consiedrato uno dei padri della scuolla delle Annales (...) Era malato pero no aveva renunciato a lavorare; un anno fa ha finito un nuovo libro di storia latinoamericana (in uscita in Messico) e cominciato una Storia d'Italia, dopo aver insegnato per trent'anni all'Universita della Sorbona e all'Ecole des Hautes Etudes, ed estato presidente dell associazione degli storici latinoamericani”. La Stampa, 6 de enero de 2002.

${ }^{2}$ Una guía bibliográfica de Romano, realizada por Alberto Filippi, computó 358 trabajos personales y una docena de obras colectivas bajo su dirección, entre 1947 y 1998, año en que cumplió 75 años. Publicado en México en Construir la historia. Ruggiero Romano homenaje, Instituto Mora/El Colegio de Michoacán/UAEM/UAM/Condumex, 1998.

${ }^{3}$ Como lo afirma Carmagnani, en su magnifica nota necrológica: Carmagnani, M. (2002). Ruggiero Romano: entre Europa y América Latina. Historia Mexicana, 52(2), 583-593.
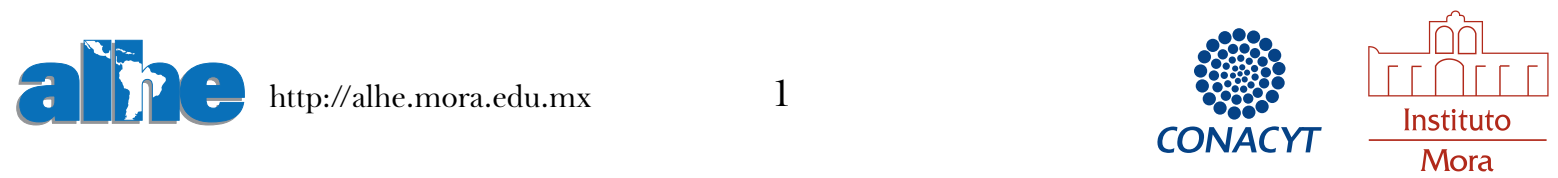
últimos textos que dejó, como botellas al mar, a lectores capaces de aprender de su cultura polémica el ejercicio de la reflexión histórica con independencia de pensamiento y sin más compromisos que con el conocimiento.

¿Pero, a la distancia de su ausencia, cuál fue su influencia en la historiografía económica? ¿Qué deuda profesional tenemos con su aporte intelectual? No es fácil responder, pero probablemente podamos distinguir algunas influencias directas e indirectas que nos expliquen su relevancia. Básicamente puedo hablar de tres: la primera, debida a su trabajo como historiador de la economía y cultura europea, que mira a Iberoamérica como alter histórico de la Europa mediterránea; la segunda, de manera indirecta, a través de su influjo en generaciones de historiadores americanistas que compartieron sus proyectos intelectuales y mediante los cuales contribuyó a crear una corriente historiográfica propia que pensara la historia americana inserta en la historia del mundo, sin ignorar lo excepcional de sus especificidades materiales y culturales, y la tercera, mediante su enseñanza directa, teñida de una pasión por el diálogo académico movido por el propósito de transmitir ideas, allí donde docencia e investigación constituyen fronteras de pensamiento y conocimiento.

Sin embargo, lo que mejor revela sus valores personales son aquellas actitudes intelectuales y éticas que marcaron decisivamente su influencia en la historiografía económica, tales como su defensa de la libertad de pensamiento, el énfasis en el rigor conceptual y la práctica intensa de una cultura de la discusión académica.

Así pues, un buen ejemplo resulta de su confesión expresa al escribir un "manual" de amplia difusión, concebido para jóvenes estudiantes de historia, en donde se planteó cómo transmitir nuevas preguntas y a la vez compatibilizar un cambio de estilo en el aprendizaje de la historia, que habría de perdurar como vocación personal en su pasión comunicativa: escribir mejor sobre "verdades en discusión" que sobre "verdades de hecho", y hacer de aquellas el vehículo de intercambio intelectual y de ruptura de pensamiento, alejadas de las modas que tanto repelió. ${ }^{4}$

La ultima década de su vida estuvo marcada en sus intereses docentes y de investigación por un retorno a Iberoamérica, y con ello a sus viejos temas, ajustando sus modelos originarios y refrendando sus polémicas tesis sobre el feudalismo americano, la crisis del siglo Xvir y la circulación monetaria $5_{5}^{5}$ El beneficio historiográfico que debemos a este último impulso intelectual puede constatarse en sus tres "últimos" libros sobre el México colonial y en la dirección de una obra colectiva, orientada de nuevo a los jóvenes, que movió a una nueva reflexión sobre nuestra historia ante las inercias historiográficas, y a "propiciar la renovación de los estudios históricos así como la critica de viejos y nuevos lugares comunes",

\footnotetext{
${ }^{4} \mathrm{~A}$ propósito se preguntaba " $\mathrm{dY}$ el joven historiador de nuestro tiempo se plantea las mismas preguntas que su maestro? ¿O - como nosotros creemos—-se ha producido una ruptura, un cambio de 'estilo', que hoy nos obliga a buscar algo nuevo? No se trata de buscar lo nuevo por el gusto de la novedad. Pero, si las exigencias del mundo que nos rodea ha cambiado, ¿no es, en cierto modo, traicionar la propia función del intelectual el seguir hablando un lenguaje que la mayoría no siente como propio y actual?” Romano, R. y Tenenti, A. (1971). Prefacio. En Los fundamentos del mundo moderno. México: Siglo XXI Editores.

${ }^{5}$ Entre sus textos relevantes, escritos en los últimos años de su vida, merecen señalarse (1993). Coyunturas opuestas. La crisis del siglo XVII en Europa e Hispanoamérica. México: Fondo de Cultura Económica/El Colegio de México; (1998). Moneda, seudomonedas y circulación monetaria en las economías de México. México: El Colegio de México y el libro póstumo (2004). Mecanismos y elementos del sistema económico colonial americano, siglos XVI-XVIII. México: Fondo de Cultura Económica-El Colegio de México.

${ }^{6}$ Romano, R. y Carmagnani, M. (1999). Componentes económicos. En Por una historia de América I. Las estructuras (pp. 160-238) y Romano, R. (1999). Componentes sociales. En Por una historia de América I. Las estructuras (pp. 288362). México: El Colegio de México.
} 
Romano fue un maestro estupendo y probablemente esta última actitud de lucha contra lugares comunes y modelos de pensamiento dibuje claramente su ejercicio docente: el amor por la discusión académica. Quienes nos beneficiamos de sus enseñanzas, supimos valorar la importancia de la duda sistemática, la deconstrucción de los modelos de pensamiento y la incomodidad de hechos y datos divergentes a las grandes ideas. Si bien Romano no concedía en la discusión, buscó expresamente persuadir con sus ideas a partir de razonar, cuestionar y replantear los problemas.

En muchos sentidos, su obra es una prolongación de esta cultura de la oralidad polémica. Si en Coyunturas opuestas (1993) hace confesión expresa de sus equívocos al juzgar que la crisis europea fue "transmitida" a América, la recuperación de la historiografía que lo desacreditaba le permitió reformular su idea de la divergencia americana en la historia de la economía mundial.7]Asimismo, su insistente énfasis en la importancia de la economía natural americana y su cuestionamiento a la existencia de una economía de mercado, incluso para el siglo XVIII tardío, se hizo expresa en un libro polémico que nació ceñido con el refrán popular adoptado por el Payo de Rosario: "No soy una onza de oro, para caerle bien a todos" 8 Y a confesión de parte, relevo de pruebas: Romano era consciente de que su libro no era una onza metálica, pero sí un libro que movería, en el mejor de los casos, a la duda y la reflexión. La crítica era algo que no le preocupaba, antes bien no la esperaba para este texto, sino una suerte de indiferencia del mundo académico que habría de esperar a "nuevos lectores" 9

Y es posible que una explicación a ello se deba al contexto historiográfico que encontró Romano a su vuelta a Latinoamérica, ya que cambió significativamente toda vez que la historiografía francesa perdió vigor, notablemente en el campo de la historia económica, frente a la influencia académica estadunidense. En su momento, Romano formuló críticas a la cliometría americana y valoró sus aportes: rechazaba la econometría aplicada a la historia, pero advertía la importancia de la reflexión histórica debida a la hipótesis contrafactual, en tanto recuperación de la idea de la opción en la historia. $\sqrt{10}$ Aunque también el uso explícito de modelos económicos, de cuantificaciones sofisticadas o de conceptos debidos a la moderna teoría económica, le producían un rechazo que se traducía en alegatos, acertijos inquietantes y críticas aceradas. Sin embargo, las divergencias de enfoque o corriente, a las que no buscaba adscribirse, no le impidieron valorar y aceptar argumentos contrarios a su visión y aprovecharlos, volviendo a replantear el problema para persuadir a su interlocutor.

Si bien ya no contaremos con su energía polémica presencial, aún nos queda la fértil posibilidad de dialogar con sus textos y recuperar de su discurso una tríada de principios: libertad de pensamiento, rigor conceptual y escrupulosidad en el manejo de fuentes y de los clásicos.

Para finalizar sin solemnidades, Romano fue tanto un inteligente crítico del pensamiento histórico dominante como un académico impolíticamente correcto: decía y escribía lo que pensaba. Eso se extraña y aprecia.

\footnotetext{
${ }^{7}$ Hemos hecho una lectura del argumento, mediante su reseña, en (1994). Cuicuilco, I(2), 241-245.

${ }^{8}$ Moneda, seudomonedas y circulación ... Una critica personal, a manera de dialogo, puede verse en Ibarra, A. (1999). Mercado colonial, plata y moneda en el siglo XVIII novohispano: comentarios para un diálogo con Ruggiero Romano, a propósito de su nuevo libro. Historia Mexicana, 49(2), 279-308 y Romano, R. (1999). Respuesta a los comentarios de Antonio Ibarra. Historia Mexicana, 49(2), 309-312.

${ }^{9}$ En ello, Carmagnani tiene sobrada razón respecto a la recepción de sus últimas obras en el medio académico mexicano.

${ }^{10}$ Romano, R. (1972). Conveniencias y peligros de aplicar los métodos de la "Nueva Historia Económica”. En La historia económica en América Latina (pp. 237-252). México: SepSetentas. Así también Romano, R. (1980). La Historia, hoy. Comunicación a la Reunión UNESCO-FLACSO [mimeo]. México, FLACSO.
} 